We suggest that chlormethiazole may have caused dysphagia by a direct action on the central mechanisms concerned in swallowing. Most reports of the adverse effects of this drug concentrate on the problems of drug abuse and addiction, ${ }^{3}$ and dysphagia has not been reported as a side effect. There have been some reports of dyspepsia, nausea, and vomiting related to the acidity of the tablets. ${ }^{4}$ This is unlikely to have been important in the present case, however, since no reflux was detected during overnight recording. Further studies are needed to investigate the prevalence and mechanism of oesophageal dysfunction in patients taking this drug.

${ }^{1} \mathrm{O}$-Svedin C. Tissue distribution of chlormethiazole, and compatibility with ethanol and certain drugs. Acta Psychiatr Scand 1966;42, suppl 192:22-34.

${ }^{2}$ Lechat P. Toxicological and pharmacological properties of chlormethiazole. Acta Psychiatr Scand 1966;192:15-25.

${ }^{3}$ Gregg E, Akter I. Chlormethiazole abuse. Br $\mathcal{F}$ Psychiatry 1979;134:627-9.

${ }^{4}$ O-Svedin C. Side effects of chlormethiazole. Acta Psychiatr Scand 1966; $192 ; 199-201$

(Accepted 18 November 1981)

University Departments of Medicine and Surgery, Hope Hospital, Salford M6 8HD

PETER DEWIS, MRCP, tutor in medicine

FRANK LOCAL, MRCP, senior registrar in medicine

DAVID C ANDERSON, FRCP, senior lecturer in medicine

JOHN BANCEWICZ, FRCS, senior lecturer in surgery

\section{Non-smoking: a feature of ulcerative colitis}

The prevalence of cigarette smoking in the United Kingdom has decreased in the past 30 years, ${ }^{1}$ but the general household survey of 1980 showed that $42 \%$ of adult males and $37 \%$ of adult females still smoked. ${ }^{2}$ Patients with Crohn's disease do not differ appreciably from the normal population in smoking habits, ${ }^{3}$ but we noticed that patients with ulcerative colitis tended to be non-smokers and therefore designed a questionnaire to assess this impression in more detail.

\section{Patients, methods, and results}

Questionnaires were sent by post to patients with ulcerative colitis and Crohn's disease, the diagnosis having been obtained from clinical records and depending on clinical assessment combined with radiology and histology. A total of 230 patients with ulcerative colitis and 192 with Crohn's disease filled in and returned the questionnaire, the response rates for the two groups being $86 \%$ and $73 \%$ respectively. A further 230 healthy patients in a fracture clinic each from a different household, also completed the questionnaire, and this control group was matched for age and sex with the patients with ulcerative colitis. Both of these groups comprised 98 male (43\%) and 132 female (57\%) patients, with a mean age of 46 years. The group with Crohn's disease did not differ statistically from these two groups, with 74 male $(39 \%)$ and 118 female $(61 \%)$ patients and a mean age of 42 years. Subjects were divided into current smokers, ex-smokers, and those who had never or only occasionally smoked, and all were asked about smoking habits of other members of the household. Smokers were asked to specify their type of tobacco and the quantity consumed each day, and patients with inflammatory bowel disease were asked whether they had started smoking before the onset of their bowel trouble. Ex-smokers were asked when they had stopped, the time relation to their bowel trouble, and reasons for stopping.

Eight per cent of patients with ulcerative colitis were current cigarette smokers compared with $42 \%$ of the group with Crohn's disease and $44 \%$ of the controls $(p<0.001)$; this low proportion in the group with ulcerative colitis was apparent at all ages (figure). Forty-eight per cent of patients with ulcerative colitis had never smoked compared with $30 \%$ of the group with Crohn's disease and $36 \%$ of the controls $(p<0.01)$. Forty per cent of patients with ulcerative colitis were ex-smokers and had stopped smoking on average 13 years earlier; the figures for the group with Crohn's disease and the controls were respectively $27 \%$ and $20 \%(p<0.01)$. In patients with ulcerative colitis $88 \%$ of current smokers and $97 \%$ of ex-smokers had started smoking before the onset of bowel trouble. Seventy-two per cent of the ex-smokers had given up before bowel symptoms began, and most had stopped for reasons of health or simply because they wished to do so.

There was a significant difference in the proportions of non-smoking households in the three groups: $76 \%$ of patients with ulcerative colitis came from non-smoking households compared with $60 \%$ of patients with Crohn's disease and $51 \%$ of controls $(p<0.001)$. This difference may partly account for the difference in current smoking between the groups, since among the patients with ulcerative colitis $82 \%$ of non-smokers came from non-smoking households whereas $78 \%$ of the smokers came from smoking households.
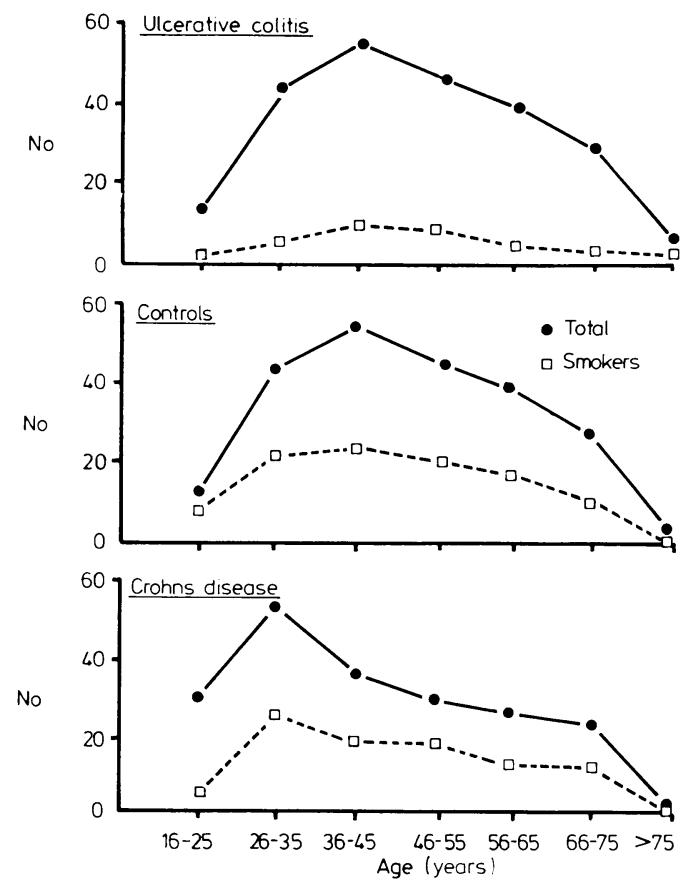

Numbers of patients with ulcerative colitis and Crohn's disease and controls in each 10-year age group who smoked cigarettes.

\section{Comment}

Cigarette smoking was uncommon in patients with ulcerative colitis, partly because a higher proportion of subjects had never smoked and also because a similar proportion had given up smoking usually before the onset of bowel symptoms. We think these findings are valid because the groups were large, the response rate was good, especially among the patients with ulcerative colitis, and patients were not specially selected. Although our control group was not matched for social class with the group with colitis, they were matched for age and sex and the prevalence of cigarette smokers (44\%) approached that in Britain in 1980 $(39 \%) .^{2}$

The reason for differences between patients with ulcerative colitis, patients with Crohn's disease, and controls is not apparent. Smoking appears to be unrelated to the onset of the bowel disorder, and smoking habits of individuals tend to reflect those in their household. Patients with ulcerative colitis have been thought to have a particular kind of personality, ${ }^{4}$ and, although more recent studies have challenged these views, ${ }^{5}$ it would be reasonable to postulate that they are more influenced by health education. Whatever the reasons may be behind these differences, the observations are relevant to studies on both morbidity and mortality in inflammatory bowel disease.

${ }^{1}$ Capell PJ. Trends in cigarette smoking in the United Kingdom. Health Trends 1978;10:49-54.

2 Office of Population and Census Surveys. Cigarette smoking 1972-1980. OPCS monitor 1981 ; No 2 . (General household survey, 1980.)

${ }^{3}$ Mayberry JF, Rhodes J, Newcombe RG. Breakfast and dietary aspects of Crohn's disease. Br Med f 1978;ii:1401.

${ }^{4}$ Engle GL. Studies of ulcerative colitis. III. The nature of the psychological processes. Am $\mathcal{F}$ Med 1955;19:231-56.

${ }^{5}$ Mendeloff AI, Monk M, Siegel CI, Lilienfield A. Illness experience and life stresses in patients with irritable colon and with ulcerative colitis. $N$ Engl f Med 1970;282:14-7.

(Accepted 18 November 1981)

Department of Gastroenterology, University Hospital of Wales, Cardiff CF4 4XW

A D HARRIES, MA, MRCP, medical registrar

A BAIRD, medical student

J RHODES, MD, FRCP, consultant physician 